\title{
Synthesis and Characterization of Hydroxyapatite Powder by Eggshell
}

\author{
Himanshu Khandelwal1 ${ }^{*}$, Satya Prakash ${ }^{2}$ \\ ${ }^{1}$ Indian Institute of Technology Bombay, Mumbai, India \\ ${ }^{2}$ Indian Institute of Technology Roorkee, Roorkee, India \\ Email: "khandelwal.iit@gmail.com
}

Received 15 January 2016; accepted 8 March 2016; published 11 March 2016

Copyright (C) 2016 by authors and Scientific Research Publishing Inc.

This work is licensed under the Creative Commons Attribution International License (CC BY). http://creativecommons.org/licenses/by/4.0/

(c) (7) Open Access

\begin{abstract}
Hydroxyapatite (HA) having chemical formula $\mathrm{Ca}_{10}\left(\mathrm{PO}_{4}\right)_{6}(\mathrm{OH})_{2}$, is the main chemical component of human bone tissue $(\mathbf{7 0 \%})$. This is the reason why it has been widely engaged in the dental and non-load bearing implantations, to cope up with the bone response as a bioactive material. In this study HA powder was synthesized by wet chemical method, using phosphoric acid $\left(\mathrm{H}_{3} \mathrm{PO}_{4}\right)$ and eggshells. The synthesized HA powder was characterized by $\mathrm{X}$-ray diffraction analysis, Scanning electron microscopy (SEM), Energy-dispersive X-ray spectroscopy (EDX) and Fourier transform (FT-IR) spectroscopy. The Thermos gravimetric analysis (TGA-DTA) was also carried out to evaluate the stability of the synthesized HA powder at higher temperatures. The results of the study indicate that sintered $\left(a{ }^{\circ} 900^{\circ} \mathrm{C}\right) \mathrm{HA}$ powder resembles the feature of pure and single apatite phase having favourable $\mathrm{Ca} / \mathrm{P}$ ratio ranging from 1.7 to 2.4 .
\end{abstract}

\section{Keywords}

Hydroxyapatite, Eggshell, Characterization, Bio-Materials, Stoichiometric Apatite

\section{Introduction}

Hydroxyapatite (HA) is the most resourceful inorganic biomaterial used for biomedical application [1]. It is a naturally occur mineral of calcium phosphate in the apatite family $\left(\mathrm{A}_{10}\left(\mathrm{BO}_{4}\right) \mathrm{X}_{2}\right)$ and regularly written as $\left.\mathrm{Ca}_{10}\left(\mathrm{PO}_{4}\right)_{6}(\mathrm{OH})_{2}\right)$ [2]. The research of biomaterial is driven mainly by the increasing demand of reconstruction material for hard tissue replacements [3] [4].

Human bone contains of $70 \%$ apatite calcium phosphate and $30 \%$ other organic elements (largely collagen). This $70 \%$ calcium phosphate resembles the crystal structure as HA [5]. The chemical and structural similarity of

"Corresponding author.

How to cite this paper: Khandelwal, H. and Prakash, S. (2016) Synthesis and Characterization of Hydroxyapatite Powder by Eggshell. Journal of Minerals and Materials Characterization and Engineering, 4, 119-126. 
HA with bone minerals, has proven to be hydroxyapatite, an attractive biomaterial for bone and tooth implantation [6]. Hydroxyapatite is highly bioactive and biocompatible with human organs. It has acknowledged a great consideration in the field of biomedical science due to its ability to form chemical bonds with hard tissue [7]. The corrosion resistant, non-carcinogenic, non-toxic, no foreign body reaction and osteoconductive properties prove the extensive use of HA for hard tissue repair [8]. At present steel, titanium and cobalt chromium based alloys are extensively used as an implant material, which are used in making hip implants, keen implant, shoulder implant and elbow implants for load bearing application [9]-[11]. But in the extended time duration problem comes regarding their functioning in body environment and durability, which leads to bring researchers' interest into bioactive and bio-inert materials for replacing metallic implants [12]-[14]. Initially ceramic and polymer materials are being used due to their light weight, corrosion resistant and bio-compatible properties; but these materials do not host the hard tissue growth [15]. Therefore HA has received great interest in orthopedic application. HA not only bonds chemically with a bone but also reduces the pain arose due to weight bearing [5] [8] [11]. In spite of this some of the other important applications of hydroxyapatite are: dental application, performing a microfiltration for water treatment, protein purification and adsorption of oxaliplatin (act as an antineoplastic agent) [16]-[22].

Many researchers have tried to synthesize the HA through various routes. Some of the conventional routes of producing HA include wet precipitation method, hydrothermal technique, low temperature synthesis, solid state reaction and sol-gel technique [5] [6] [23]-[27]. In many of the techniques, final HA phase is obtained only after calcination at $1200^{\circ} \mathrm{C}$, whereas some techniques are unreasonably time consuming and end up with the formation of undesirable anions [1] [6]. Few researchers have also used eggshell for chemically synthesizing HA [26].

A huge amount of eggshells is left daily, which are of no use and produce waste. These eggshells support microbial action and lead to pollute environment. Annually around 250,000 tons of eggshell are only produced annually by food processing industry. Eggshell corresponds to $11 \%$ of the total weight of an egg. These eggshells mainly contain calcium carbonate $(91 \%-94 \%)$, calcium phosphate $(1 \%)$ and other organic matters, which makes it preferable for synthesizing $\mathrm{CaO}$ [23] [24]. Therefore, in this study an attempt has been made to use this waste eggshell as a calcium source for synthesizing highly pure and nanocrystalline HA powder. Further, the synthesized HA powder was characterized using XRD, TG-DTA, SEM and FTIR.

\section{Materials and Methods}

The experimental procedure is divided into three parts which deals with preparation of $\mathrm{CaO}$ from egg shell, synthesis of $\mathrm{HA}$ powder from $\mathrm{CaO}$ and phosphoric acid, and characterization of $\mathrm{HA}$ powder.

\subsection{Synthesis of CaO from Eggshell}

The major constituent exists in the eggshell is $\mathrm{CaCO}_{3}$, which accounts nearby $94 \%$ of the overall weight. Thus, in this method hen's eggshells were used to synthesis $\mathrm{CaO}$. The uncrushed eggshells were taken in bulk and cleaned by hand with deionized water. It was then boiled in water for about half an hour in an oven, showing in Figure 1(a).

Further the cleaned eggshells were kept in a porcelain vessel and were calcined in a tube furnace at $900^{\circ} \mathrm{C}$ for one hour, showing in Figure 1(b). The eggshell evolves carbon dioxide beyond $850^{\circ} \mathrm{C}$ and converted into calcium oxide [28]. The expected reaction occurred was as follows:

$$
\mathrm{CaCO}_{2} \rightarrow \mathrm{CaO}+\mathrm{CO}_{2} \uparrow
$$

\subsection{Synthesis of HA}

A measured amount of calcined eggshell power was taken in a beaker and dispersed in distilled water. This stoichiometry amount was decided in accordance with the quantity of calcium present in the calcined eggshell. In this reaction the $\mathrm{CaO}$ transforms into $\mathrm{Ca}(\mathrm{OH})_{2}$ as shown in below equation [29].

$$
\mathrm{CaO}+\mathrm{H}_{2} \mathrm{O} \rightarrow \mathrm{Ca}(\mathrm{OH})_{2}+\text { Heat }
$$

The reagent grade $0.6 \mathrm{M}$ solution of orthophosporic acid was added to the $\mathrm{Ca}(\mathrm{OH})_{2}$ solution. The drop wise solution was added at a precise rate, to decrease the $\mathrm{pH}$ of the solution up to 8.5. The precipitation formation was observed at this point. Further, the solution was kept for 24 hours at ambient temperature, which cause the 


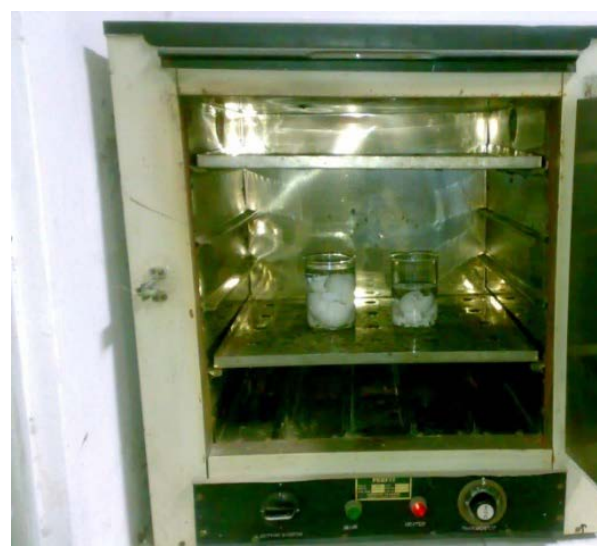

(a)

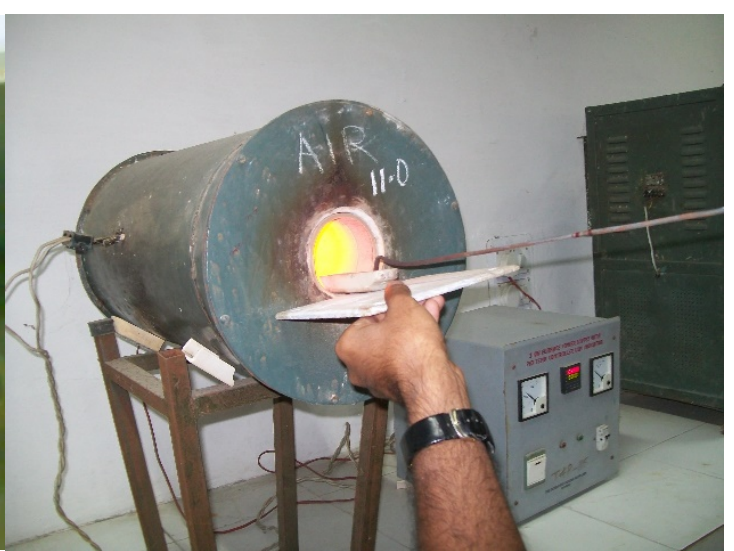

(b)

Figure 1. Synthesis of CaO: (a) Eggshell boiling in oven; (b) Calcination of HA in tube furnace.

precipitation hardening. The solution was further stirred for another 30 minute on a magnetic stirrer and then left over for another 24 hour, which helps to complete the formation of precipitation. The expected reaction for this process is as follows [30].

$$
10 \mathrm{Ca}(\mathrm{OH})_{2}+6 \mathrm{H}_{3} \mathrm{PO}_{4} \rightarrow \mathrm{Ca}_{10}\left(\mathrm{PO}_{4}\right)_{6}(\mathrm{OH})_{2}+18 \mathrm{H}_{2} \mathrm{O}
$$

The precipitate was filtered with filter paper and washed carefully with double distilled water and again filtered using filter paper. The precipitation was again kept in the oven for 2 hours at $100^{\circ} \mathrm{C}$ for drying. The dried precipitation was further calcined at $900^{\circ} \mathrm{C}$ for 2 hours in the tube furnace as Figure $1(\mathrm{~b})$. At the end of the process the white crystalline agglomerates were found in the crucible. The complete process chart is represented in Figure 2.

\subsection{Characterization of HA}

The morphological characterization of the HA powder was conducted using the field emission scanning electron microscope (Quanta 200; FE-SEM). The phase composition of HA powder was determined using X-Ray Diffraction Analysis (Bruker D-8 Advanced; XRD, Germany), which uses $40 \mathrm{kV}$ voltage, $30 \mathrm{~mA}$ electron probe current and $\mathrm{Cu}$ target. Thermal stability and weight loss of the HA was estimated using thermo gravimetric analysis data (Perkin Elmer Elan DRC 6000; TG-DTA). The $10^{\circ} \mathrm{C} / \mathrm{min}$ heating rate was applied in air atmosphere, up to the $1400^{\circ} \mathrm{C}$ temperature. The Fourier Transform-Infrared Spectroscopy (Thermo NICOLET 5700; FTIR) technique is used to identify the organic and inorganic functional group present in the HA powder. FTIR transmittance spectra of the HA powder samples were reported in the $4000-400 \mathrm{~cm}^{-1}$ region by using $\mathrm{KBr}$ pellet technique. The technique measures the absorption of infrared radiation by the sample material versus wave number. The infrared absorption bands identify molecular components and structures. The elemental analysis of the HA was conducted by the same FE-SEM instrument equipped with energy dispersive X-ray spectroscopy (EDX) system. All of the facility was used at the Institute Instrumentation Centre, IIT Roorkee.

\section{Result \& Discussion}

\subsection{X-Ray Diffraction Analysis}

The chemical reaction of $\mathrm{CaO}$ in Ortho phosphoric acid solution produces a white colour solid material. The material is having porous construction of the grains of irregular diameter. The X-ray diffraction of the sample is shown in Figure 3. The data were collected for the $2 \theta$ in the range from $15^{\circ} \mathrm{C}$ to $80^{\circ} \mathrm{C}$. The XRD pattern shows an intense reflection peak in between the $31.8^{\circ}-32.5^{\circ}$ of $2 \theta$ values, which resembles the characteristic peak of the apatite phase. The result also agrees with the previous literature [5].

\section{Determination of Particle Size}

Determination of particle size was done by using the Debye-Scherrer formula represented by Equation (4). The particle sizes calculated for the corresponding peaks are represented in Table 1 . The average particle size of 


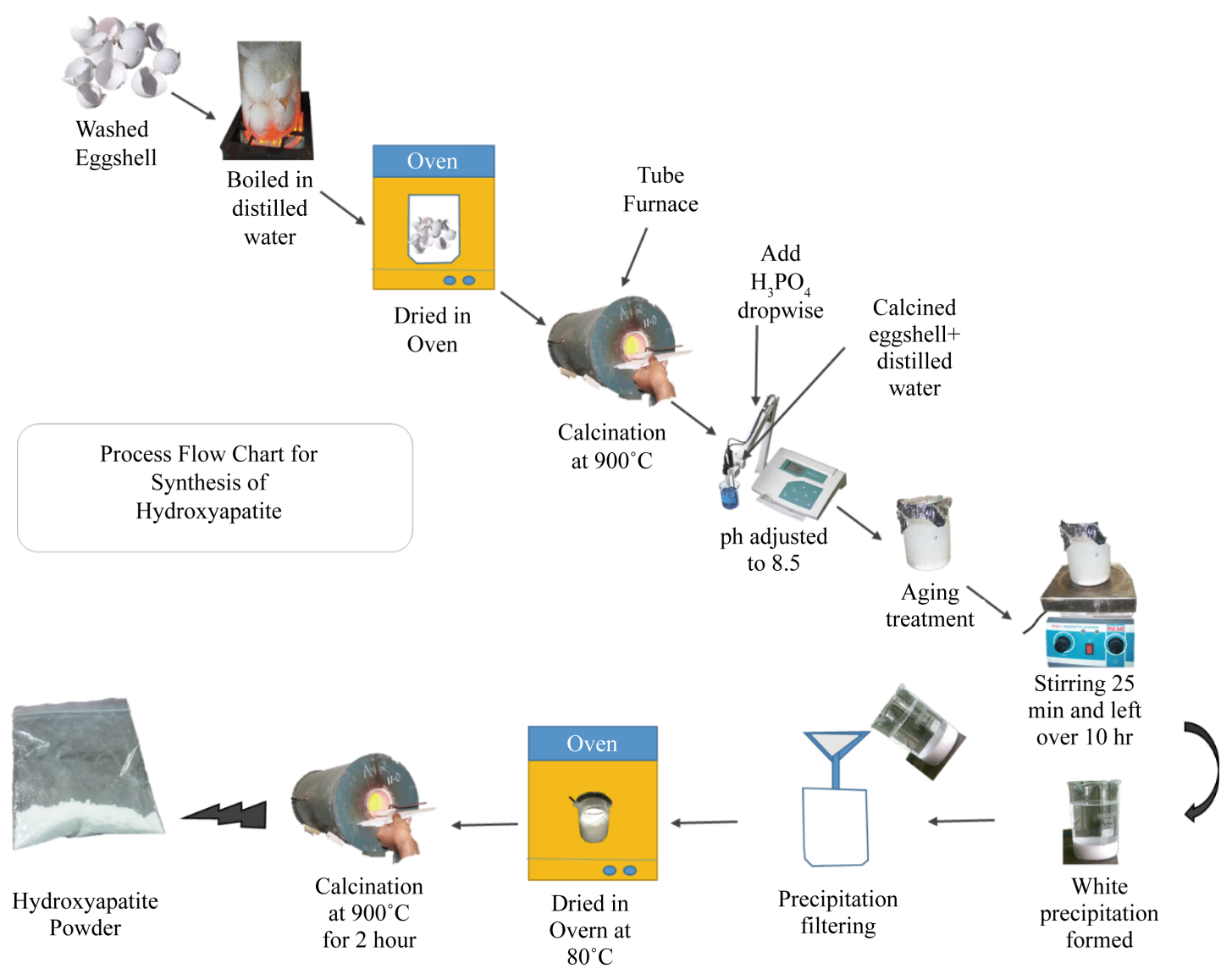

Figure 2. Schematic Process flow chart for synthesis of HA Powder by Eggshell and $\mathrm{H}_{3} \mathrm{PO}_{4}$.

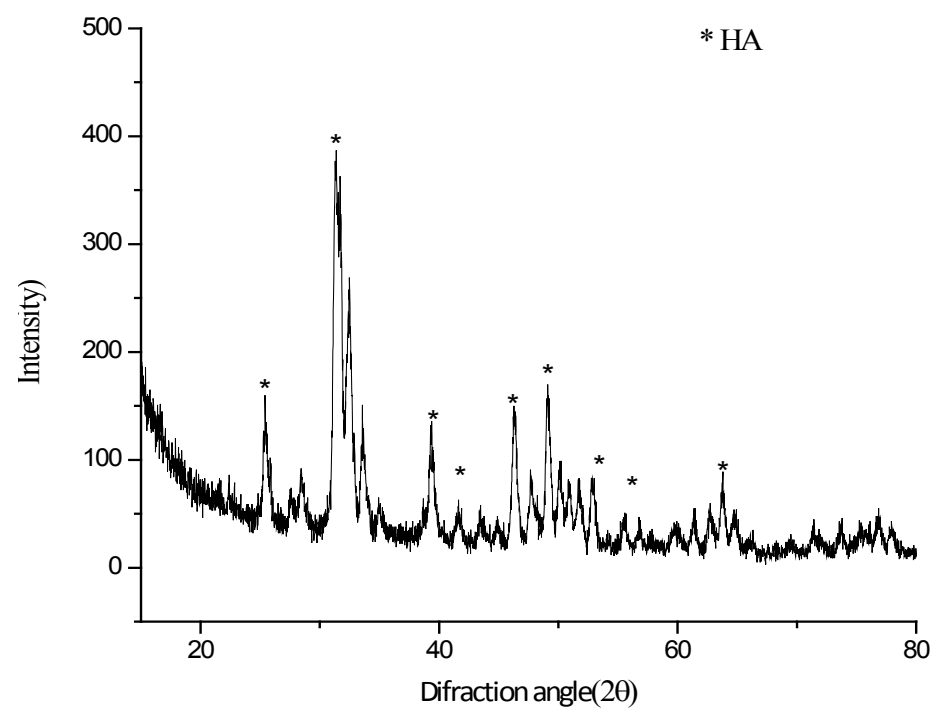

Figure 3. X-ray diffraction pattern synthesized powder.

synthesized HA powder is around $31.5 \mathrm{~nm}$.

$$
\text { Partical Size }=\frac{0.9^{*} \lambda}{b \cos \theta} \quad[31]
$$


Table 1. Determination of particle size.

\begin{tabular}{cccc}
\hline Diffraction angle in degree $(\mathbf{2} \boldsymbol{\theta})$ & B (FWHM) in $\left(^{\circ}\right)$ & b in radian $\left(\mathbf{1 0}^{-3}\right)$ & $\begin{array}{c}\text { Particle size } \\
\mathbf{D}=(\mathbf{0 . 9} * \boldsymbol{\lambda}) / \boldsymbol{b} \cos \boldsymbol{\theta}(\mathbf{n m})\end{array}$ \\
\hline 25.369 & 0.2429 & 4.237 & 35 \\
31.376 & 0.367 & 6.402 & 23 \\
39.372 & 0.333 & 5.809 & 26 \\
46.259 & 0.341 & 5.948 & 30 \\
49.102 & 0.306 & 5.338 & 49 \\
63.793 & 0.199 & 3.482 & 26 \\
\hline
\end{tabular}

Average Particle Size $=(35+23+26+26+30+49) / 6=31.5 \mathrm{~nm}$.

Here $\lambda=0.154 \mathrm{~nm}$ for copper $\mathrm{k} \alpha$, and $b=$ FWHM (full wave half maximum width), and $\theta=$ Diffraction angle (Here for FWHM the machine factor is 0.1 ).

\subsection{FTIR Analysis}

Figure 4 represents the FTIR Spectra of the Hydroxyapatite samples. The graph shows broad bands around $1643.48 \mathrm{~cm}^{-1}$ and $3449.01 \mathrm{~cm}^{-1}$, indicates adsorbed $\mathrm{H}_{2} \mathrm{O}$ in the samples. The peak at $878.26 \mathrm{~cm}^{-1}$ and 1460.87 $\mathrm{cm}^{-1}$ are corresponding to vibration mode $\mathrm{CO}_{3}^{2-}$ ion. These peaks are ill defined which confirms the elimination of $\mathrm{CO}_{3}^{2-}$ due to the calcination of $\mathrm{HA}$ at higher temperature of $900^{\circ} \mathrm{C}$. The stretching bond corresponding to $\mathrm{OH}$ is at $3570.35 \mathrm{~cm}^{-1}$, which is overlapping with the band at $3449 \mathrm{~cm}^{-1}$ due to adsorbed water. The band at 633.14 is also due to structural $\mathrm{OH}$ in HA. These peaks confirm the hydroxyapatite [5] [15]. The peak at 926.81 indicates the starching mode of $\mathrm{PO}_{4}^{3-}$ and at 568.53 relates to bending mode of $\mathrm{PO}_{4}^{3-}$. The larges parting distance of these bands revels the crystalline phase [5] [15].

\subsection{EDX Analysis}

The elemental analysis of the chemically produced HA powder is shown in Figure 5. The result represents the amount of calcium and phosphorus present in the sample. The weight and atomic percentage are also reported in the Figure 5. The EDX result shows the $\mathrm{Ca} / \mathrm{P}$ ratio around 1.68 which is below 2 and acceptable. The ideal $\mathrm{Ca} / \mathrm{P}$ ratio of HA is 1.67 .

\subsection{SEM Micrograph}

The SEM images of synthesized hydroxyapatite powder are shown in Figure 6. The images are taken at 500× and $10000 \times$ magnification. The nanocrystalline HA can be clearly observed from the images. The produced HA powder has bulky nature, as it is found to be made by nanocrystalline molecules and forms microcrystalline molecule. The agglomerates of irregular shapes were found which have a tendency of leaving pores in between. The formations of pores are advantageous since they permit the tissue growth on implants inside the body, when it is used as a biomaterial.

\subsection{TG-DTA Analysis}

The thermos gravimetric analysis was used for evaluating the thermal stability and weight loss of the HA samples. The heating rate of $10^{\circ} \mathrm{C} / \mathrm{min}$ was employed up to $1400^{\circ} \mathrm{C}$ temperature in air atmosphere. It can be clearly observed from the DTA-TG analysis (show in Figure 7), that there is a weight loss of about $2 \%$ up to $600^{\circ} \mathrm{C}$ temperature, which is due to the evaporation of absorbed water; and $1.8 \%$ in the range $600^{\circ} \mathrm{C}$ to $1400^{\circ} \mathrm{C}$ which is due to change of HA to $\alpha / \beta$-TCP. No major loss was found up to $1400^{\circ} \mathrm{C}$. More or less stable curvature was observed within the temperature range, that shows the thermal stability of HA powder.

\section{Conclusion}

This research work presents a chemical method to produce pure, stoichiometry and stable HA powder using 


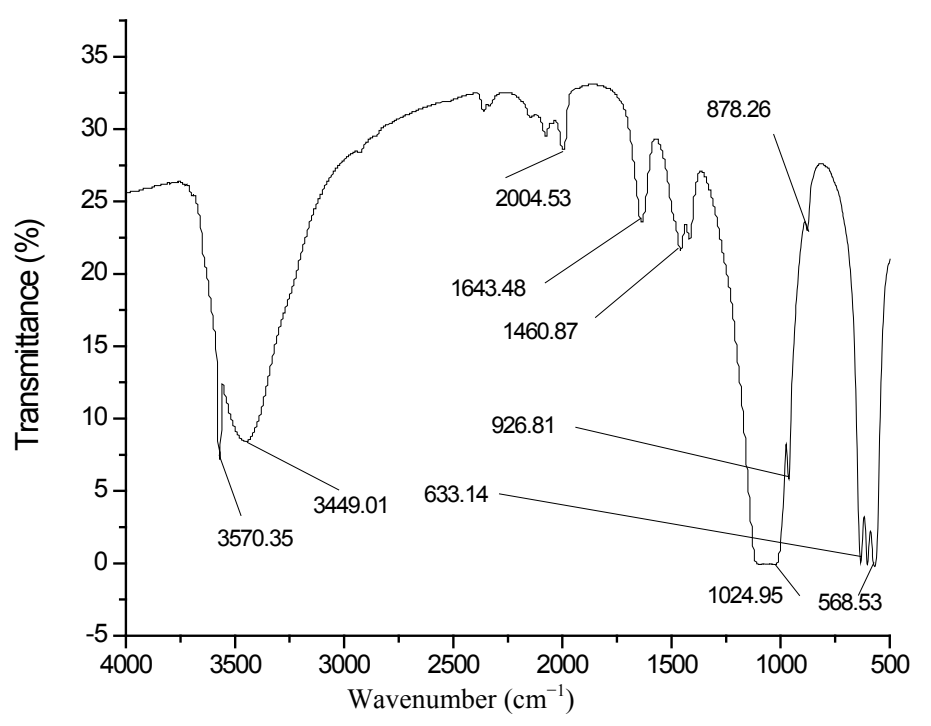

Figure 4. FT-IR spectra of HA powder.

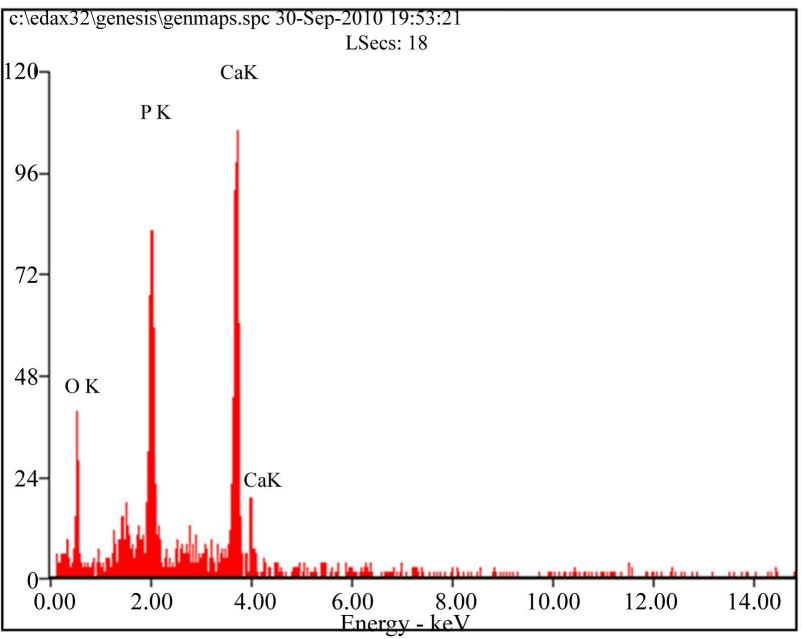

\begin{tabular}{|c|l|l|}
\hline Element & $W t \%$ & $A t \%$ \\
\hline$O K$ & 40.82 & 61.42 \\
\hline$P K$ & 22.06 & 16.56 \\
\hline$C a K$ & 37.12 & 22.02 \\
\hline Matrix & Correction & ZAF \\
\hline
\end{tabular}

Figure 5. EDX analysis of HA powder.

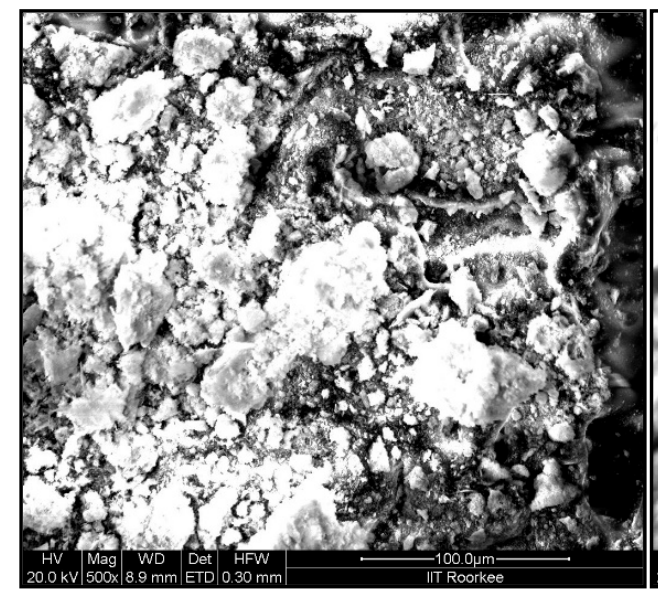

(a)

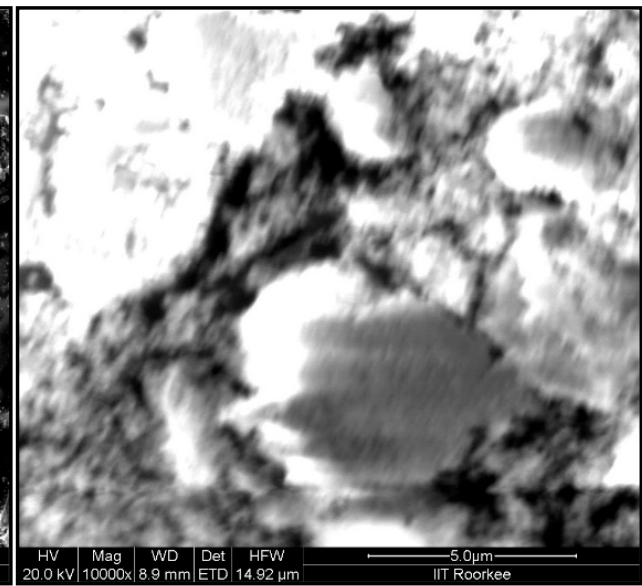

(b)

Figure 6. SEM micrograph depicts morphology of HA powder at (a) $500 \times$ and (b) $10000 \times$. 


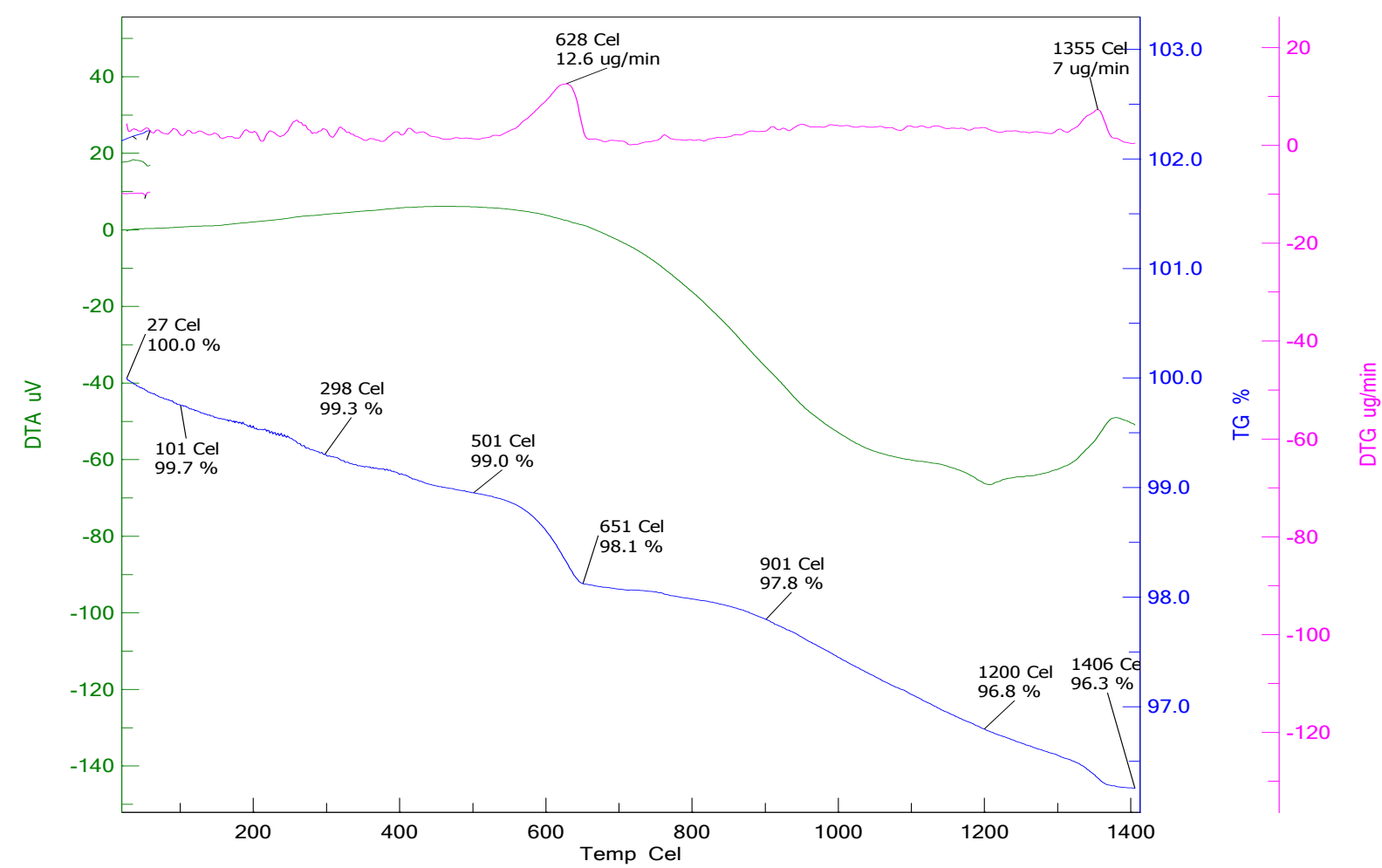

Figure 7. Thermal analysis of HA powder.

eggshell and orthophosphoric acid. The XRD result reviles the crystallinity and the FTIR analysis evidences the phase purity of HA powder. From the EDX test of hydroxyapatite powder the ratio of $\mathrm{Ca}$ and $\mathrm{P}$ was found around 1.68. This is in an acceptable range, as in the ideal HA the weight ratio of $\mathrm{Ca}$ and $\mathrm{P}$ is 1.67. From the SEM analysis the prepared HA powder is found to be nanocrystalline nature. The TG-DTA analysis had been carried out and its results revealed thermal stability of the powder. The research shows the eggshell as a possible recycling material for producing HA powder, which can also help in waste management and keeping environment clean.

\section{References}

[1] Agrawal, K., Singh, G., Prakash, S. and Puri, D. (2012) Synthesis of Ha by Various Sol-Gel Techniques and Their Comparison: A Review. International Journal of Surface Engineering \& Materials Technology, 2, 27-32.

[2] Ben-Nissan, B. (2003) Natural Bioceramics: From Coral to Bone and Beyond. Current Opinion in Solid State and Materials Science, 7, 283-288. http://dx.doi.org/10.1016/j.cossms.2003.10.001

[3] Nath, S. and Basu, B. (2008) Designing Materials for Hard Tissue Replacement. Journal of the Korean Ceramic Society, 45, 1-29. http://dx.doi.org/10.4191/KCERS.2008.45.1.001

[4] Khandelwal, H., Singh, G., Agrawal, K., Prakash, S. and Agarwal, R.D. (2013) Characterization of Hydroxyapatite Coating by Pulse Laser Deposition Technique on Stainless Steel 316 L by Varying Laser Energy. Applied Surface Science, 265, 30-35. http://dx.doi.org/10.1016/j.apsusc.2012.10.072

[5] Prabakaran, K., Balamurugan, A. and Rajeswari, S. (2005) Development of Calcium Phosphate Based Apatite from Hen'S Eggshell. Bulletin of Materials Science, 28, 115-119. http://dx.doi.org/10.1007/BF02704229

[6] Agrawal, K., Singh, G., Puri, D. and Prakash, S. (2011) Synthesis and Characterization of Hydroxyapatite Powder by Sol-Gel Method for Biomedical Application. Journal of Minerals \& Materials Characterization \& Engineering, 10, 727-734.

[7] Kokubo, T., Kim, H.-M. and Kawashita, M. (2003) Novel Bioactive Materials with Different Mechanical Properties. Biomaterials, 24, 2161-2175. http://dx.doi.org/10.1016/S0142-9612(03)00044-9

[8] Sun, L., Berndt, C.C., Gross, K.A. and Kucuk, A. (2001) Material Fundamentals and Clinical Performance of PlasmaSprayed Hydroxyapatite Coatings : A Review. Journal of Biomedical Materials Research, 58, 570-592. 
[9] Horowitz, E. and Parr, J.E. (1994) Characterization and Performance of Calcium Phosphate Coatings for Implants (ASTM STP 1196). American Society for Testing and Materials, Philadelphia.

[10] Oonishi, H. (1991) Orthopaedic Applications of Hydroxyapatite. Biomaterials, 12, 171-178. http://dx.doi.org/10.1016/0142-9612(91)90196-H

[11] Jayabalan, M., Shalumon, K.T., Mitha, M.K., Ganesan, K. and Epple, M. (2010) Effect of Hydroxyapatite on the Biodegradation and Biomechanical Stability of Polyester Nanocomposites for Orthopaedic Applications. Acta Biomaterialia, 6, 763-775. http://dx.doi.org/10.1016/j.actbio.2009.09.015

[12] Long, M. and Rack, H. (1998) Titanium Alloys in Total Joint Replacement-A Materials Science Perspective. Biomaterials, 19, 1621-1639. http://dx.doi.org/10.1016/S0142-9612(97)00146-4

[13] Amini, A.R., Wallace, J.S. and Nukavarapu, S.P. (2011) Short-Term and Long-Term Effects of Orthopedic Biodegradable Implants. Journal of Long-Term Effects of Medical Implants, 21, 93-122. http://dx.doi.org/10.1615/JLongTermEffMedImplants.v21.i2.10

[14] Hench, L.L. (1991) Bioceramics: From Concept to Clinic. Journal of the American Ceramic Society, 74, $1487-1510$. http://dx.doi.org/10.1111/j.1151-2916.1991.tb07132.x

[15] Saeed, A.M., Hassan, R.A. and Thajeel, K.M. (2011) Synthesis of Calcium Hydroxyapatite Powder from Hen's Eggshell. Iraqi Journal of Physics, 9, 24-28.

[16] Van Landuyt, K.L., Snauwaert, J., De Munck, J., Peumans, M., Yoshida, Y., Poitevin, A., et al. (2007) Systematic Review of the Chemical Composition of Contemporary Dental Adhesives. Biomaterials, 28, 3757-3785. http://dx.doi.org/10.1016/j.biomaterials.2007.04.044

[17] Sadat-Shojai, M., Atai, M., Nodehi, A. and Khanlar, L.N. (2010) Hydroxyapatite Nanorods as Novel Fillers for Improving the Properties of Dental Adhesives: Synthesis and Application. Dental Materials, 26, 471-482. http://dx.doi.org/10.1016/i.dental.2010.01.005

[18] Betsiou, M., Sikalidis, C. and Papageorgiou, A. (2007) Adsorption of Oxaliplatin by Hydroxyapatite. Bioautomation, 8, 138-145.

[19] Barroug, A. and Glimcher, M.J. (2002) Hydroxyapatite Crystals as a Local Delivery System for Cisplatin: Adsorption and Release of Cisplatin in Vitro. Journal of Orthopaedic Research, 20, 274-280. http://dx.doi.org/10.1016/S0736-0266(01)00105-X

[20] Bajpai, P.K. and Benghuzzi, H.A. (1988) Ceramic Systems for Long-Term Delivery of Chemicals and Biologicals. Journal of Biomedical Materials Research, 22, 1245-1266. http://dx.doi.org/10.1002/jbm.820221212

[21] Ma, N., Zhang, Y., Quan, X., Fan, X. and Zhao, H. (2010) Performing a Microfiltration Integrated with Photocatalysis Using an $\mathrm{Ag}-\mathrm{TiO}(2) / \mathrm{HAP} / \mathrm{Al}(2) \mathrm{O}(3)$ Composite Membrane for Water Treatment: Evaluating Effectiveness for Humic Acid Removal and Anti-Fouling Properties. Water Research, 44, 6104-6114. http://dx.doi.org/10.1016/j.watres.2010.06.068

[22] Yusuf, P., Dahlan, K. and Witarto, A. (2009) Application of Hydroxyapatite in Protein Purification. Makara Journal of Science, 13, 134-140.

[23] Sasikumar, S. and Vijayaraghavan, R. (2006) Low Temperature Synthesis of Nanocrystalline Hydroxyapatite from Egg shells by Combustion Method. Trends in Biomaterials and Artificial Organs, 19, 70-73.

[24] Rivera, E.M., Araiza, M., Brostow, W., Castaño, V.M., Díaz-Estrada, J., Hernández, R., et al. (1999) Synthesis of Hydroxyapatite from Eggshells. Materials Letters, 41, 128-134. http://dx.doi.org/10.1016/S0167-577X(99)00118-4

[25] Hui, P., Meena, S.L., Singh, G., Agarawal, R.D. and Prakash, S. (2010) Synthesis of Hydroxyapatite Bio-Ceramic Powder by Hydrothermal Method. Journal of Minerals and Materials Characterization and Engineering, 9, 683-692. http://dx.doi.org/10.4236/jmmce.2010.98049

[26] Raihana, M.F., Sopyan, I., Hamdi, M. and Ramesh, S. (2008) Novel Chemical Conversion of Eggshell to Hydroxyapatite Powder. International Federation for Medical and Biological Engineering Proceedings, 21, 333-336.

[27] Ferraz, M.P., Monteiro, F.J. and Manuel, C.M. (2004) Hydroxyapatite Nanoparticles: A Review of Preparation Methodologies. Journal of Applied Biomaterials and Biomechanics, 2, 74-80.

[28] Ahmed, S. and Ahsan, M. (2009) Synthesis of Ca-Hydroxyapatite Bioceramic from Eggshell and Its Characterization. Bangladesh Journal of Scientific and Industrial Research, 43, 501-512. http://dx.doi.org/10.3329/bjsir.v43i4.2240

[29] Dasgupta, P., Singh, A., Adak, S. and Purohit, K.M. (2004) Synthesis and Characterization of Hydroxyapatite Produced from Eggshell. Proceedings of the International Symposium of Research Students on Materials Science and Engineering, 1-6.

[30] Bahrololoom, M.E., Javidi, M., Javadpour, S. and Ma, J. (2009) Characterisation of Natural Hydroxyapatite Extracted from Bovine Cortical Bone Ash. Journal of Ceramic Processing Research, 10, 129-138.

[31] Cullity, B.D. and Stock, S.R. (2001) Elements of X-Ray Diffraction. Prentice Hall, Upper Saddle River. 